\title{
Research on Gas Hydrate Plug Formation under Pipeline-Like Conditions
}

\author{
Florian Stephan Merkel, ${ }_{1}$ Carsten Schmuck, ${ }^{2}$ Heyko Jürgen Schultz, ${ }^{1}$ \\ Timo Alexander Scholz, ${ }^{1}$ and Sven Wolinski ${ }^{1}$ \\ ${ }^{1}$ University of Applied Sciences Niederrhein, 47798 Krefeld, Germany \\ ${ }^{2}$ University Duisburg-Essen, 45141 Essen, Germany \\ Correspondence should be addressed to Florian Stephan Merkel; florian.merkel@hs-niederrhein.de
}

Received 30 July 2015; Revised 30 October 2015; Accepted 17 November 2015

Academic Editor: Bhaskar Kulkarni

Copyright ( 2015 Florian Stephan Merkel et al. This is an open access article distributed under the Creative Commons Attribution License, which permits unrestricted use, distribution, and reproduction in any medium, provided the original work is properly cited.

Hydrates of natural gases like methane have become subject of great interest over the last few decades, mainly because of their potential as energy resource. The exploitation of these natural gases from gas hydrates is seen as a promising mean to solve future energetic problems. Furthermore, gas hydrates play an important role in gas transportation and gas storage: in pipelines, particularly in tubes and valves, gas hydrates are formed and obstruct the gas flow. This phenomenon is called "plugging" and causes high operational expenditure as well as precarious safety conditions. In this work, research on the formation of gas hydrates under pipeline-like conditions, with the aim to predict induction times as a mean to evaluate the plugging potential, is described.

\section{Introduction}

Due to the discovery of enormous gas hydrate reservoirs and the simultaneous shortage of conventional fossil fuels, research on hydrates of natural gases (gas hydrates) has become focus of industry and economy.

But this promising future energy carrier also causes problems, mainly in gas-transporting pipelines. Because gas hydrates form at high pressures and low temperatures, they can block pipelines in deep sea or permafrost regions, especially after bends and valves. This so-called plugging leads to critical operating conditions and high operating expenditure and may even lead to accidents with fatal consequences. Plugging can be prevented in pipelines by using different methods of inhibition, for example, by heating or insulating the critical pipeline areas or by adding inhibiting chemicals (like methanol). All of those conventional methods of hydrate inhibition either are very expensive or can pose risks for the environment. Therefore, the trend in the last years is to so-called "low dosage hydrate inhibitors (LDHI)." To better prevent plugging in pipelines and for optimizing pipeline operation, it is critical to predict the formation time of hydrates in pipelines. However, the prediction of hydrate formation time in pipelines causes difficulties, since so far, the hydrate formation mechanism still has not been conclusively proven and hence only limited predictability of the kinetic phenomena is given for a concrete application [14].

Therefore it is essential to investigate the hydrate formation under pipeline-like conditions, especially regarding the development of inhibitors to reduce or eliminate the plugging problem. In this work, extensive research on the formation of methane hydrate under pipeline-like conditions has been carried out. Induction times (as critical parameter for the evaluation of plugging phenomena) have been determined. The insights gained in this work will be used to generate a prognosis model for the formation of hydrate plugs. This model shall be used as a reference for the evaluation of customized hydrate inhibitors. Here, an innovative and new approach of this research project is to permanently integrate appropriate inhibitors as a coating in the most endangered pipeline regions. 


\section{Gas Hydrates}

2.1. Composition of Gas Hydrates. Gas hydrates are crystalline solids, in which guest molecules (like methane) are trapped inside of cages made up of water molecules, which are bound together by hydrogen bonds. The guest molecules stabilize the cages; an empty cage is thermodynamically instable. Depending on the type of guest molecule and the environmental conditions, different hydrate structures are formed. The structures differ in size, number of water molecules per unit cell, and the arrangement of the hydrate cages. In this work, only the hydrate structure I (s I, simple cubic structure) is of importance, since methane (as the main component of natural gas) as guest leads to the formation of $s$ I hydrate. The structure contains two types of cages (labeled "A" and "B" in Table 1), one "small" and one "large" cage type, which differ in size, number of water molecules, and the type of faces that form a cage (see Table 1) [1,3-5].

The hydration number describes the ratio of water molecules per unit cell to the number of guest molecules which are entrapped in the cages, assuming all the cages are filled with one guest molecule and is a basis for calculating the storage capacity of hydrates. However, it describes an ideal state, in which empty cages are not accounted for. In reality, there is usually only one guest molecule per cage (with only a few exceptions), but not all of the cages are filled $[1,4]$.

2.2. Formation of Gas Hydrates. According to the current state of knowledge, gas hydrate formation occurs in two phases, similar to crystallization processes [1].

During the so-called "nucleation phase," crystal nuclei are formed. When a critical nucleus size is reached, the "hydrate growth phase" begins. For the detailed description of hydrate formation, several theories exist, for example, the "labile cluster hypothesis" [1] or the so-called "blob theory" [6]. However, it can be said that the actual mechanism still remains unexplained to this day.

One important criterion for the design of experiments is the stochastic nature of hydrate formation processes. It is in no way trivial to predict induction times. Hence, large numbers of experiments at different conditions are needed. Therefore, in this work one focus was also on determining "optimal" experimental parameters with the lowest standard deviation for the later development of a prediction model based on those parameters. "Optimal" in this case means that the driving force for hydrate formation in the system was adjusted to facilitate hydrate formation with lower standard deviation of formation times and also to accelerate hydrate formation in the system.

2.3. Induction Times. The most important criterion for research on gas hydrate formation kinetics is the so-called induction time. The induction time is the time between the start of an experiment (corresponding to the point in a pipeline, where the water-gas-mixture would enter the hydrate stability zone, regarding pressure and temperature) and the onset of hydrate formation, which is indicated by a rise of the temperature (due to the exothermic nature of
TABLE 1: Properties of hydrate structure I (s I).

\begin{tabular}{lcc}
\hline & \multicolumn{2}{c}{ Structure I } \\
\hline Cage labeling & A (small) & B (big) \\
Cage description & $5^{12}$ & $5^{12} 6^{2}$ \\
Composition of unit cell & $2 \mathrm{~A} * 6 \mathrm{~B} * 46 \mathrm{H}_{2} \mathrm{O}$ \\
Hydration number & \multicolumn{2}{c}{5.75} \\
\hline
\end{tabular}

TABLE 2: Measurement variables and accuracy; Parr 4568.

\begin{tabular}{|c|c|c|}
\hline Parameter & Sensor & Accuracy \\
\hline $\begin{array}{l}\text { Stirrer torque } \\
M\end{array}$ & Parr DR-2500 & $0.10 \%$ \\
\hline Pressure $p$ & $\begin{array}{c}\text { Ashcroft OEM-Pressure } \\
\text { Transducer G2 }\end{array}$ & $\begin{array}{c}1 \% \text { of terminal value } \\
( \pm 2 \text { bar })\end{array}$ \\
\hline $\begin{array}{l}\text { Temperature } \\
T\end{array}$ & Juchheim PT100 & $\begin{array}{c}0.3 \text { to } 0.8 \% \text { of } \\
\text { measured value } \\
\text { (at experimental } \\
\text { conditions) }\end{array}$ \\
\hline Mass $m$ & Sartorius LE1003 & $\pm 0.001 \mathrm{~g}$ \\
\hline $\begin{array}{l}\text { Conductivity } \\
\delta \\
\end{array}$ & $\begin{array}{c}\text { inoLab-cond } 740 \\
\text { WTW TetraCon } 325\end{array}$ & $\begin{array}{c} \pm 1 \% \text { of measured value } \\
\mathrm{n} / \mathrm{a}\end{array}$ \\
\hline Mass flow & $\begin{array}{c}\text { Bronkhorst Mättig Mini } \\
\text { Cori-Flow }\end{array}$ & $\begin{array}{l}\leq 1.12 \% \text { of measured } \\
\text { value }\end{array}$ \\
\hline
\end{tabular}

hydrate formation) with a simultaneous decrease in pressure (due to the "consumption" of gas while gas is being trapped in hydrate cages). Therefore, the focus of this work is on determining induction times under varying system conditions (pressure, temperature, and so forth).

\section{Materials and Methods}

Since the induction times are specific for the "reaction" system, the used equipment is described below.

For conducting the experiments, a stirred reactor of the type 4568, manufactured by Parr Instrument (Deutschland), came to use (see Figure 1). It can operate at pressures ranging from 0 to $200 \mathrm{bar}(\mathrm{g})$ and at temperatures ranging from -10 to $+150^{\circ} \mathrm{C}$. Heating and cooling were done by a thermostat of the type Presto A40 manufactured by Julabo, which is connected to a PT100-temperature sensor inside the reactor and therefore directly controls the reactor inner temperature. The reactor is equipped with a hollow shaft stirrer for gas input. Pressure $p[\operatorname{bar}(\mathrm{g})]$, temperature $T$ (measured as voltage signal $[V])$, rotational frequency $n\left[\mathrm{~min}^{-1}\right]$, and stirrer torque $M[\mathrm{Ncm}]$ are recorded every second. The accuracy of measurements is shown in Table 2. In addition, the reactor is equipped with two glass windows for visual observation of the process.

Pressurization occurs with simultaneous measurement of gas flow. For this, a Coriolis type mass flow meter manufactured by Bronkhorst Mättig was used. For weighing 
TABLE 3: Induction times of four exemplary series of measurements.

\begin{tabular}{|c|c|c|c|c|c|c|c|c|}
\hline \multirow{2}{*}{$\begin{array}{l}\text { Experimental conditions/series } \\
\text { of measurement }\end{array}$} & \multicolumn{8}{|c|}{ Induction time [min] } \\
\hline & 1 & 2 & 3 & 4 & 5 & 6 & 7 & 8 \\
\hline $160 \mathrm{bar}(\mathrm{g}) 4^{\circ} \mathrm{C}$ & 248 & 138 & 150 & 87 & 107 & - & - & - \\
\hline $160 \operatorname{bar}(\mathrm{g}) 6^{\circ} \mathrm{C}$ & 158 & 110 & 139 & 108 & 105 & - & - & - \\
\hline $135 \mathrm{bar}(\mathrm{g}) 4^{\circ} \mathrm{C}$ & 278 & N.f. & 2783 & N. f. & 1590 & 876 & 268 & 301 \\
\hline $120 \mathrm{bar}(\mathrm{g}) 4^{\circ} \mathrm{C}$ & 2889 & 1888 & 641 & 1123 & 361 & - & - & - \\
\hline
\end{tabular}

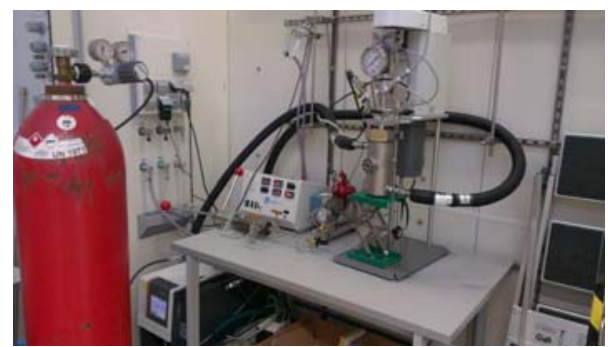

FIgURE 1: Reactor Parr 4568.

water, a scale of the type LE1003s, manufactured by Sartorius AG Deutschland, was used.

Experiments were conducted at temperatures of 4 and $6^{\circ} \mathrm{C}$, which are realistic values for deep sea pipelines. Pressures ranged from 120 to $160 \mathrm{bar}(\mathrm{g})$.

To simulate pipeline-like conditions, the experimental procedure was as follows.

Methane (in a purity of $\geq 99.5 \%$, provided by Messer Industriegase) and water (Milli-Q water with a conductivity $\delta$ of $1-3 \mu \mathrm{S} / \mathrm{cm}$ ) were filled in the reactor at $20^{\circ} \mathrm{C} \pm 0.5^{\circ} \mathrm{C}$ and slowly cooled to experimental temperature to simulate the temperature drop in the pipeline from the drilling point onwards and between compressor stations in the pipeline. The resulting pressure drop from cooling and dissolution of methane in water then corresponds to the pressure drop inside the pipeline.

To guarantee turbulence inside the reactor, the stirrer operates at high frequency, and a modified Reynolds number of approximately 1974 is reached (see (1)):

$$
\begin{aligned}
\operatorname{Re}_{R} & =\frac{n * d_{R}^{2} * \rho}{\eta} \\
& =\frac{(200 / 60 \mathrm{~s}) *\left(3.0 * 10^{-2} \mathrm{~m}\right)^{2} * 1000\left(\mathrm{~kg} / \mathrm{m}^{3}\right)}{1.52 * 10^{-3}(\mathrm{~kg} /(\mathrm{m} * \mathrm{~s}))} \\
& \approx 1974 .
\end{aligned}
$$

To ascertain statistically significant results, multiple measurements (at least 5 per experimental series) were conducted. In each of those experiments, fresh water was used to avoid the so-called memory effect.

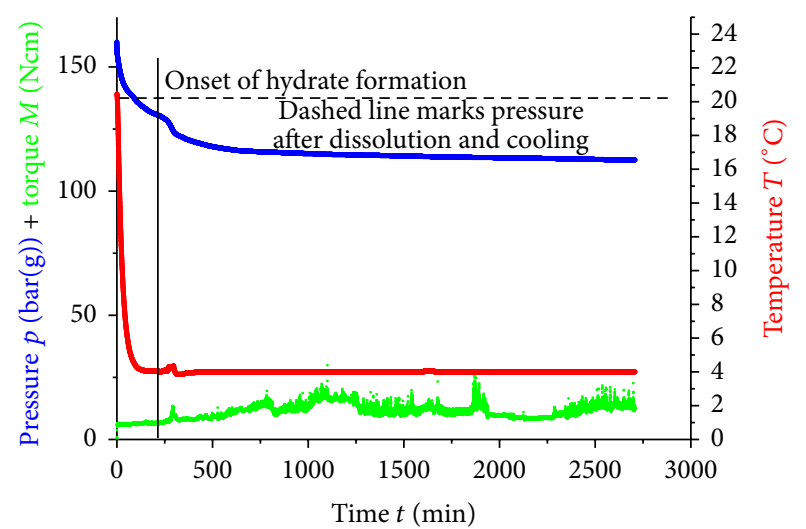

FIgURE 2: Example of hydrate formation experiment.

\section{Results and Discussion}

The evaluation of results is shown exemplarily for one experiment. The determined induction times are then shown in Table 3.

Figure 2 shows pressure and stirrer torque (1st ordinate) as well as temperature (2nd ordinate) plotted against time $t$ (abscissa). Starting point of each experiment is the point of highest pressure, before cooling to target temperature. The pressure drop in the beginning is caused by dissolution of methane in water as well as cooling to the "target" temperature of $4^{\circ} \mathrm{C}$; the dashed line in Figure 2 highlights the obtained pressure. Below, the calculation is shown exemplarily for a pressure of $160 \mathrm{bar}(\mathrm{g})$ and a target temperature of $4^{\circ} \mathrm{C}$ (as in Figure 2).

With a molar amount of methane (measured by Coriolis mass-flow meter) of 3.06 mole, a starting temperature $T$ of $293.15 \mathrm{~K}$, and a volume of $0.35 \mathrm{dm}^{3}$, the theoretical starting pressure $p_{\text {start }}$ (without influence of dissolution) is calculated (the van-der-Waals-coefficients were taken from [7]):

$$
\begin{aligned}
& p_{\text {start }}
\end{aligned}
$$

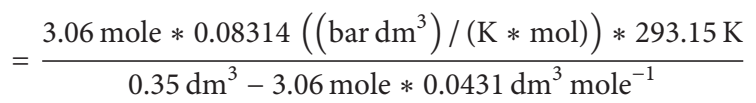

$$
\begin{aligned}
& -\frac{2.303 \mathrm{bar} \mathrm{dm}^{6} \mathrm{~mole}^{-2} * 3.06^{2} \mathrm{~mole}^{2}}{0.35^{2} \mathrm{dm}^{6}}=165.6 \mathrm{bar} \text {. }
\end{aligned}
$$


In a next step, the pressure is calculated for a temperature of $4^{\circ} \mathrm{C}$ and a molar amount of 3.06 mole, by use of the vander-Waals-equation:

$$
\begin{aligned}
& p_{4^{\circ} \mathrm{C}} \\
& =\frac{3.06 \mathrm{~mole} * 0.08314\left(\left(\mathrm{bardm}^{3}\right) /(\mathrm{K} * \text { mole })\right) * 277.15 \mathrm{~K}}{0.35 \mathrm{dm}^{3}-3.06 \mathrm{~mole} * 0.0431 \mathrm{dm}^{3} \mathrm{~mole}^{-1}} \\
& \quad-\frac{2.303 \mathrm{bar} \mathrm{dm}^{6} \mathrm{~mole}^{-2} * 3.06^{2} \mathrm{~mole}^{2}}{0.35^{2} \mathrm{dm}^{6}}=147.2 \text { bar. }
\end{aligned}
$$

This corresponds to the pressure change caused by the cooling process.

The dissolution of methane is considered as follows.

According to Lange's handbook of chemistry [8], the dissolubility coefficient for methane at $4^{\circ} \mathrm{C}$ is $\lambda_{1}=$ $0.003467123[\mathrm{~g} / 100 \mathrm{~g}$ water $\cdot \mathrm{bar}]$.
The effects of dissolubility and cooling add up to a "total" pressure reduction, based on the theoretical starting pressure of 165.6 bar.

Based on the conditions of no hydrate formation taking place and water being only existent as liquid phase, the dissolved amount of methane in water $\left(m_{\mathrm{H}_{2} \mathrm{O}}=249.5 \mathrm{~g}\right)$ accounts to

$$
\begin{aligned}
c_{w_{1}} & =\lambda \cdot p_{K_{1}} \cdot \frac{m_{\mathrm{H}_{2} \mathrm{O}}}{100} \\
& =0.003467123 * 165.6 \cdot \frac{249.5}{100} \frac{\mathrm{g} \cdot \mathrm{bar} \cdot \mathrm{g}}{\mathrm{g} \cdot \mathrm{bar}} \approx 1.43 \mathrm{~g} .
\end{aligned}
$$

This corresponds to a molar amount of $n_{\text {dissolution }}=$ 0.09 mole. The pressure after dissolution of methane is then calculated as follows:

$$
\begin{aligned}
& p=\frac{\left(n_{\text {start }}-n_{\text {dissolution }}\right) * R * T}{V-\left(n_{\text {start }}-n_{\text {dissolution }}\right) * b}-a \frac{\left(n_{\text {start }}-n_{\text {dissolution }}\right)^{2}}{V^{2}} \\
& p_{\text {dissolution }, 4^{\circ} \mathrm{C}}=\frac{(3.06-0.09) \text { mole } * 0.08314\left(\left(\text { bar dm }^{3}\right) /(\mathrm{K} * \text { mole })\right) * 293.15 \mathrm{~K}}{0.35 \mathrm{dm}^{3}-(3.06-0.09) \mathrm{mole}^{2} 0.0431 \mathrm{dm}^{3} \mathrm{~mole}^{-1}} \\
& -\frac{2.303 \text { bar dm }^{6} \mathrm{~mol}^{-2} *(3.06-0.09)^{2} \mathrm{~mole}^{2}}{0.35^{2} \mathrm{dm}^{6}} \\
& p_{\text {dissolution }, 4^{\circ} \mathrm{C}}=160.2 \text { bar. }
\end{aligned}
$$

The total pressure reduction (based on the theoretical starting pressure of 165.6 bar) then amounts to

$$
\begin{aligned}
\Delta p_{4^{\circ} \mathrm{C}}= & p_{\text {start }, 20^{\circ} \mathrm{C}}-p_{\text {dissolution }, 4^{\circ} \mathrm{C}}+p_{\text {start }, 20^{\circ} \mathrm{C}} \\
& -p_{\text {cooling }, 4^{\circ} \mathrm{C}} \\
\Delta p_{4^{\circ} \mathrm{C}}= & (165.6-160.2+165.6-147.2) \text { bar } \\
= & 23.8 \text { bar. }
\end{aligned}
$$

This equals the experimental data in good approximation.

A "successful" hydrate formation is characterized by a pressure drop with simultaneous rise (peak) in temperature (marked by the vertical line in Figure 2). The temperature peak is caused by the exothermic nature of hydrate formation, which, in the beginning of the macroscopic formation phase, is faster and more intense than the temperature controlling thermostat can handle. The pressure drop with simultaneous temperature rise also marked the induction time.

Table 3 shows exemplarily the induction times of four series of experiments. Experiment 6 at 135 bar(g) was conducted to gain a higher statistical certainty because of the high variance in this series of measurement. "N. f." in experiments 7 and 8 at $135 \operatorname{bar}(\mathrm{g})$ means "no formation of gas hydrates during experimental time." Table 4 shows the corresponding statistical parameters of all experiments with successful hydrate formation. All series of experiments were normally distributed and had no outliers according to the Dixon-Q-test (level of significance was 0.95).

Analysis of the results shows that the measurements conducted at 160 bar(g) possess the lowest mean deviation and therefore the "best" predictive accuracy for the induction time of all experiments shown. These experimental parameters seem to be a promising basis for the development of a hydrate prediction model in the system used.

The experiments conducted at $160 \mathrm{bar}(\mathrm{g})$ and $6^{\circ} \mathrm{C}$ possess an even lower standard deviation than those conducted at $160 \mathrm{bar}(\mathrm{g})$ and $4^{\circ} \mathrm{C}$. This seems surprising, since the temperature driving force for hydrate formation is higher at $4^{\circ} \mathrm{C}$ than at $6^{\circ} \mathrm{C}$, which should also be reflected in a reduced standard deviation. It should be noted, however, that the first experiment conducted at $4^{\circ} \mathrm{C}$ has a very high induction time of $248 \mathrm{~min}$, which greatly influences the mean induction time and standard deviation.

Also, $4^{\circ} \mathrm{C}$ is a more realistic "field value" for the operation of deep sea pipelines, since $4^{\circ} \mathrm{C}$ is the water temperature in the relevant depth. Therefore, we recommend experiments at $4^{\circ} \mathrm{C}$ as future reference for inhibitor testing as well as the development of a prediction model.

The increase of the standard deviation in the experimental series at 135 and 120 bar(g) could be explained by the lower driving force of the hydrate formation at lower pressures. So 
TABLE 4: Statistical parameters of four exemplary series of measurements.

\begin{tabular}{|c|c|c|c|c|c|c|c|}
\hline & Mean [min] & $\begin{array}{c}\text { Standard } \\
\text { deviation } \\
{[\mathrm{min}]}\end{array}$ & Minimum [min] & Median [min] & Maximum [min] & $\begin{array}{c}\text { Normally } \\
\text { distributed? }\end{array}$ & Outlier? \\
\hline $160 \operatorname{bar}(\mathrm{g}) 4^{\circ} \mathrm{C}$ & 146 & 62 & 87 & 138 & 248 & Yes & No \\
\hline $160 \operatorname{bar}(\mathrm{g}) 6^{\circ} \mathrm{C}$ & 124 & 23 & 105 & 110 & 158 & Yes & No \\
\hline $135 \operatorname{bar}(\mathrm{g}) 4^{\circ} \mathrm{C}$ & 1016 & 1009 & 268 & 588 & 2783 & Yes & No \\
\hline $120 \operatorname{bar}(\mathrm{g}) 4^{\circ} \mathrm{C}$ & 1381 & 1023 & 361 & 1123 & 2889 & Yes & No \\
\hline
\end{tabular}

effects like the presence of possible nucleation sites could have a stronger effect.

In any case, the experimental conditions at 135 and 120 $\operatorname{bar}(\mathrm{g})$, respectively, are deemed unsuitable for the development of a prediction model because of the high standard deviation.

\section{Conclusions}

Extensive series of measurements were carried out to investigate the formation of gas hydrates under pipeline-like conditions. Measurements showed that higher pressures lead to a decrease in standard deviation of the experiments. One possible explanation could be the higher driving force of hydrate formation at higher pressures so that effects like the distribution of nucleation sites have lower significance.

In any case, the experiments provide a good basis for further deepening research. The development of a prediction model for hydrate formation in the used reaction system to precisely determine induction times in advance is the next logical step. To achieve this goal, the mechanism of hydrate formation has to be further elucidated.

In the end, the goal of the experiments should be the development of a new customized hydrate inhibitor to better prevent pipeline plugging in the future. In this context, different chemical substances will be tested concerning their inhibition potential. The influence of certain functional molecular groups will be evaluated. For the first time, inhibitors tested with the above-mentioned method shall be permanently applied in the existing pipeline coatings to minimize the disadvantages of common hydrate inhibitors (as mentioned in Section 1) and establish a new and innovative method of hydrate inhibition in pipelines.

\section{Conflict of Interests}

The authors declare that there is no conflict of interests regarding the publication of this paper.

\section{Acknowledgment}

The authors gratefully acknowledge the financial support of their efforts provided by a research program of the University of Applied Sciences Niederrhein.

\section{References}

[1] E. D. Sloan and C. A. Koh, Clathrate Hydrates of Natural Gases, CRC Press, Boca Raton, Fla, USA, 3rd edition, 2008.

[2] E. D. Sloan, Natural Gas Hydrates in Flow Assurance, Gulf Professional Publishing, Elsevier, Burlington, Mass, USA, 2011.

[3] F. S. Merkel and H. J. Schultz, "Methane extraction from natural gas hydrate reservoirs with simultaneous storage of carbon dioxide," Chemie Ingenieur Technik, vol. 87, no. 4, pp. 475-483, 2015.

[4] H. J. Schultz, Zum Gashydratabbau mittels Mammut-PumpenPrinzip, Fraunhofer-IRB, Stuttgart, Germany, 2004.

[5] E. D. Sloan, C. A. Koh, A. K. Sum, A. L. Ballard, G. J. Shoup, and N. McMullen, "Hydrates: state of the art inside and outside flowlines," Journal of Petroleum Technology, vol. 61, no. 12, pp. 89-94, 2009.

[6] L. C. Jacobson, W. Hujo, and V. Molinero, "Amorphous precursors in the nucleation of clathrate hydrates," Journal of the American Chemical Society, vol. 132, no. 33, pp. 11806-11811, 2010.

[7] P. W. Atkins and J. de Paula, Physikalische Chemie, Wiley, Weinheim, Germany, 4th edition, 2006.

[8] J. A. Dean and N. A. Lange, Lange's Handbook of Chemistry, McGraw-Hill, New York, 15th edition, 1999. 

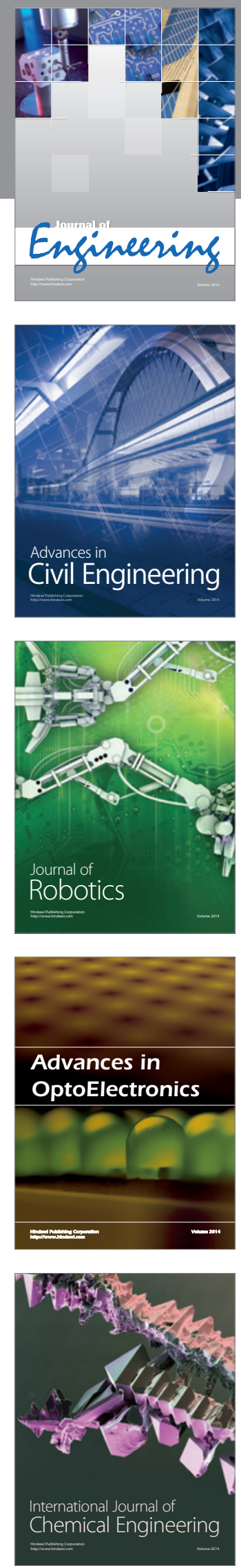

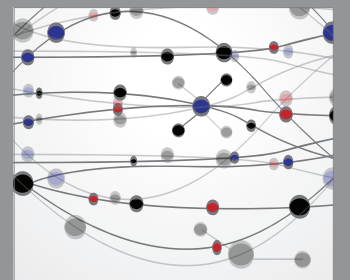

The Scientific World Journal
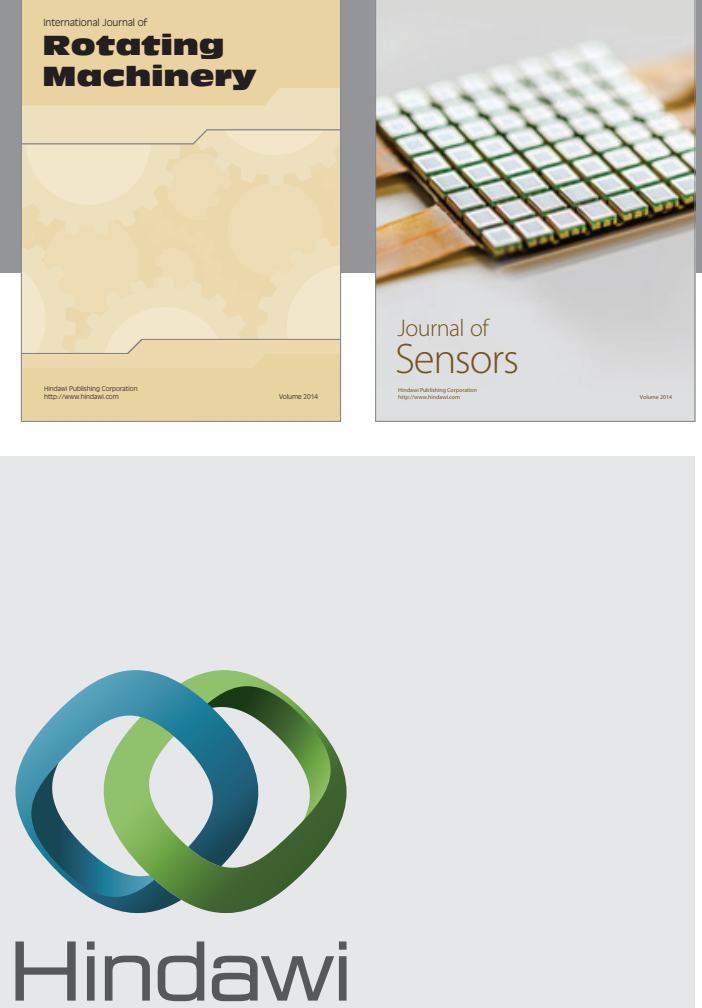

Submit your manuscripts at http://www.hindawi.com
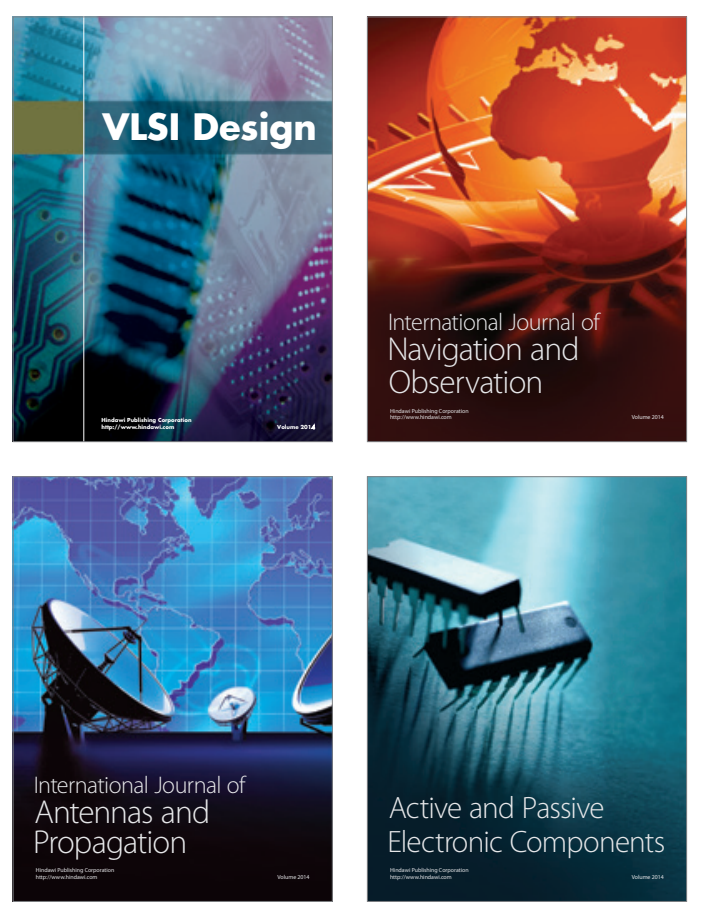
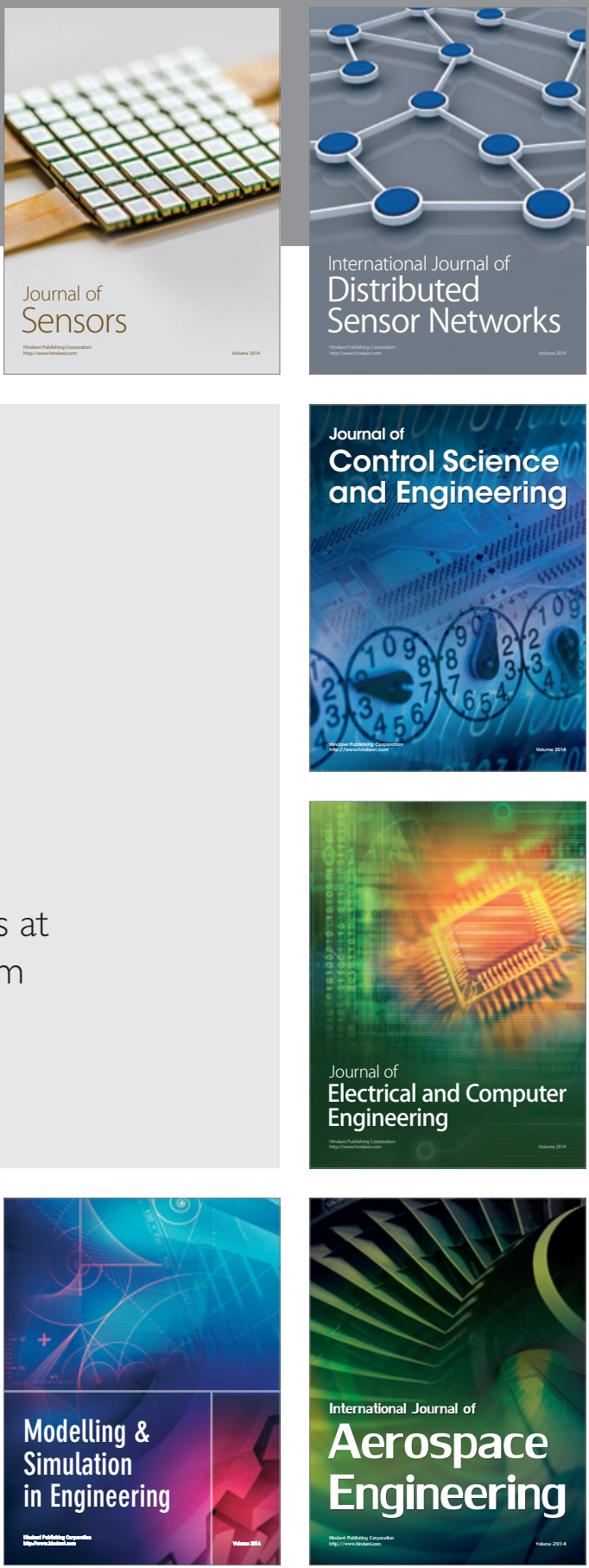

Journal of

Control Science

and Engineering
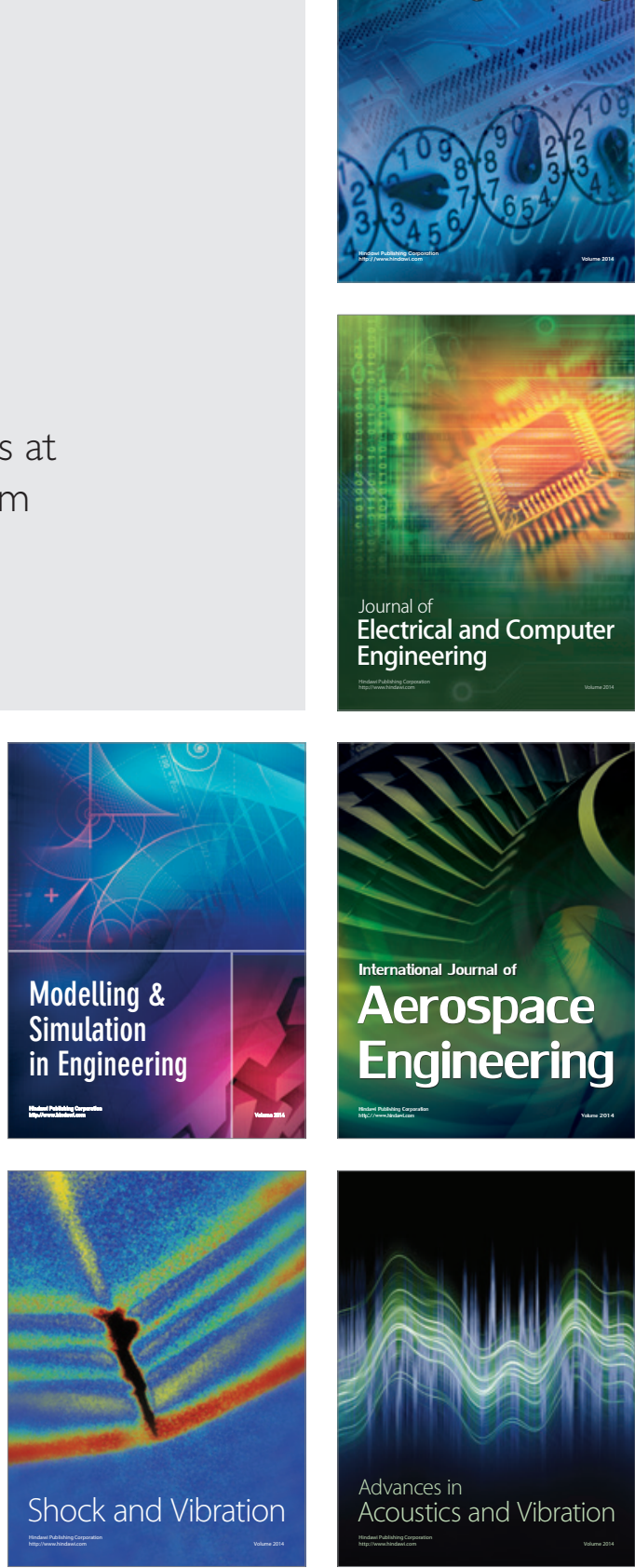